concerned. Countryside Conflicts, too, clearly seeks to influence the course of rural events. Where, then, would the two books lead us?

Countryside Conflicts takes the view that conservation should be an operative principle of all land management, not a separate element within reserves and designated sites. This requires a change in direction and purpose of forestry and agriculture. Much of the authors' writing implies a conservative view of the landscape: they seek mechanisms to maintain hill farming and thereby keep the landscape we have. To make this possible they nevertheless show some willingness to sacrifice the wild, for example by advocating grants which would support initial operations such as draining, fencing and planting. They are against conifer afforestation in the uplands, but support broadleaf afforestation in the lowlands, only hinting at how they would avoid setting this woodland on surviving fragments of semi-natural habitat. Indeed, throughout they are vague about what should physically be done on the land.

There is little doubt about Rackham's sense of value. He appreciates the antique features, which have "meaning", particularly the natural elements and timehonoured associations between man and nature. His attitude is exemplified by the claim that "ten thousand oaks of 100 years old are not a substitute for one 500-yearoid oak", with the implication that they are less valuable. Inevitably he is scathing about the effects of modern agriculture "fertility comes in a sack" - - and considers not only that it should not be extended but that it should retrench towards more conservative forms of land management.

This is all very well. Many people, including myself, understand these very points and sympathize with his attitudes. Experience has taught us, however, that many others value a single 100 -year-old oak above its 500-year-old grandparent, both as timber and scenery. Such people see beauty in order, cultivation and production, and rejoice in increased productivity of farmland and plantations. Others again seek refreshment and beauty in wilderness, and would minimize the effects of man. Rackham sees variety, significance (the latter-day "scientific interest"), permanence and security in traditional conservative use of resources, and thereby rejects both views: it is valuable to have his corner so cogently argued.

Vague though they are on the practicalities, these books converge in their antagonism to much of modern agriculture and forestry, and their support of the semi-wilderness maintained by traditional practices. Living with nature is the modern theme of conservation.

George Peterken is in the Chief Scientist's Directorate, Nature Conservancy Council, Northminster House, Peterborough PEI IUA, UK.

\section{The need to know about lipids}

\section{Howard Goldfine}

Biochemistry of Lipids and Membranes. Edited by Dennis E. Vance and Jean E. Vance. Benjamin/Cummings:1985. Pp.593. $\$ 34.95, £ 34.95$.

INTEREST in lipids among biochemists and molecular biologists appears to go through cycles ranging from high enthusiasm to near neglect. Recently, a decided upturn in awareness can be detected. Although the phosphatidylinositol cycle has been studied for 30 years, its physiological significance has only recently come to wider notice. Adding to this increase in attention being paid to lipids have been the ripple effects of discoveries on the arachidonate cascade, the regulation of cholesterol biosynthesis and the molecular biology of the low-density lipoprotein receptor, and the finding that the plateletactivating factor is an ether lipid analogue of phosphatidylcholine.

The appearance of a substantial volume devoted to the biochemistry of lipids and membranes will be welcomed not only by those who have long engaged in lipid research, but also by those who have been drawn to it by following leads in such areas as viral tumorogenesis and hormonal regulation, or by a desire to understand how membranes are assembled and how they work. The editors set themselves a double goal - to produce a text for use in advanced biochemistry courses devoted to lipid and membrane biochemistry, and a reference volume for basic and clinical researchers. They have largely succeeded in meeting the second objective by having each of the 15 chapters written by knowledgeable and active specialists. The information is up to date and the subjects are presented in considerable depth, backed up by references to recent reviews and primary publications. As might be expected in a multi-authored work, some contributors show a tendency to advance their own views, but the balance is generally reasonable.

While the need for a text at this level may not extend to many graduate programmes in the biomedical sciences, where such courses exist or are contemplated this volume will prove very useful for both students and their teachers. Most of the chapters begin with a brief historical essay touching on key developments and figures in the field concerned, and end with a discussion of future directions and areas in need of further development. In addition to chapters on traditional areas of lipid metabolism, there are helpful articles on the assembly of membrane lipids and proteins, and a good but somewhat abbreviated discussion of the physical properties and functional role of lipids in membranes

A recurrent theme in the book is the paucity of information (with a few notable exceptions) that we have on the regulation of lipid metabolism, either at the level of the gene or by modulation of enzyme activities. Students looking for research problems in cell biology will readily find them here. The tools for solving such problems are becoming more sophisticated through the development of methods for solubilizing and purifying membrane proteins, the production of monoclonal antibodies, and the ability to isolate and clone the genes for the proteins of lipid metabolism. Answers may not come easily but, as this volume makes clear, the search should be both stimulating and rewarding.

Howard Goldfine is a Professor in the Department of Microbiology, University of Pennsylvania School of Medicine, Philadelphia, Pennsylvania 19104, USA.

\section{Dishing the dirt}

\section{Richard P. Wayne}

Atmospheric Chemistry and Physics of Air Pollution. By John H. Seinfeld. Wiley: 1986. Pp.738. \$59.95, £57.45.

JoHN Seinfeld defines air pollution as "any atmospheric condition in which substances are present at concentrations high enough ... to produce a measurable effect on man, animals, vegetation, or materials". Dusts, pollen, smoke and volcanic gases and ash can undoubtedly exert deleterious effects, although they are part of the "natural" atmosphere. Mankind has, however, discovered all manner of means of further polluting the atmosphere on scales ranging from the local to the truly global. Seinfeld's hope is that the scientific study of pollution will provide pointers to finding the optimum way of abating the problem in its manifold forms.

Research into air pollution encompasses several disciplines that are only loosely connected, and Seinfeld makes a determined effort to show how the different facets relate to each other. He first considers the sources of pollution, and the effects that various pollutants have on atmospheric properties, on materials, on vegetation and, above all, on human health. Often, the substances released as primary pollutants are not themselves the agents of damage. Rather, chemical transformations are responsible for the formation of a secondary species that is harmful. Such transformations range from the production of acids from the oxides of nitrogen and sulphur accompanying the com- 